\title{
Assessment of the Regime of Functioning Agroecosystems Depending on the Climate and Technogenic Pollution of the Soils
}

\author{
Lubov V. Pomazkina, Lada G. Sokolova, Yulia V. Semenova \\ Siberian Institute of Plant Physiology and Biochemistry, Siberian Branch of Russian Academy of Sciences, \\ Irkutsk, Russia \\ Email: Ivp@sifibr.irk.ru
}

Received 27 August 2014; revised 10 September 2014; accepted 25 September 2014

Copyright (C) 2014 by authors and Scientific Research Publishing Inc.

This work is licensed under the Creative Commons Attribution International License (CC BY).

http://creativecommons.org/licenses/by/4.0/

(c) (i) Open Access

\section{Abstract}

Some results of monitoring (for the period from 1992 to 2005) related to transformations of carbon in agroecosystems of Baikal Siberia (Russia) characterized by unpolluted grey forest soils as well as the soils technogenically polluted with heavy metals are discussed with use the unique approach to integrated assessment of the agroecosystem's functioning regime. The peculiarities of accumulation of carbon in soil microbial biomass and $\mathrm{CO}_{2}$ emission during the years differing in climate conditions are demonstrated. Analysis of formation of net-mineralized and (re)immobilized carbon is conducted, their ratio being used for the purpose of assessment of the level of influence upon the agroecosystem. The agroecosystems having technogenically polluted soils are characterized by processes of the soil microbial biomass reduction and by an obvious increase of $\mathrm{CO}_{2}$ emission into the atmosphere. Negative changes, which are bound up with carbon transformation, are intensified under unfavorable climate conditions. Intensification of processes of carbon net mineralization and, vice versa, lowering the intensity of processes related to carbon (re)immobilization (especially under the effect of soil pollution and climate changes) provoke instability of the agroecosystem and cause formation of a new regime of its functioning.

\section{Keywords}

Agroecosystems, Regime of Functioning, Integral Assessment, Technogenic Pollution, Climate Changes

\section{Introduction}

The negative anthropogenic impact on land ecosystems is known to be bound up not only with technogenic pol- 
lution of the environment but also with variations of climate conditions. Dynamic variations of greenhouse gas concentration in the atmosphere are considered to be the main factor, which influence the climate [1]-[4]. In this connection, one of the objectives presumed by the Kioto Protocol (1992) was to lower the $\mathrm{CO}_{2}$ emission into the atmosphere. Meanwhile, all the principal sources of this emission were not revealed completely, and assessment of the variations observed and expected for each of the countries was also absent. The problem of greenhouse gases is acute and still not solved for the territory of Russia, what is conditioned by substantial diversity of the natural and climate conditions.

Presently, the international scientific community relates the problem to not only technogenic $\mathrm{CO}_{2}$ emission but also to the growth of carbon flow from the anthropogenic transformed ecosystems [5] [6]. For example, it is known, the intensity of mineralization processes in technogenically polluted soils in the agroecosystems grows, what is accompanied with the increase of $\mathrm{CO}_{2}$ emission and emission of nitrogen oxides into the atmosphere and also with the reduction of the processes related to (re)immobilization of carbon and nitrogen [7]. Presently, the quantitative assessment of the $\mathrm{CO}_{2}$ emission and emission of nitrogen oxides in ecosystems (while including agroecosystems) is fragmentary. Meanwhile, this assessment—on account of above diversity of conditions—is needed. It is especially urgent for obtaining representative data and computing the balance of carbon in various soil-climate regions of Russia [8] [9].

The importance of investigations related to carbon transformation in agroecosystems, which has become especially obvious in recent decades [6] [10] [11], is conditioned by abrupt changes of the natural environment and the climate. The attention to the processes of technogenic pollution-a kind presently obviously negative factor, which influence the processes of carbon transformations-is still insufficient. There is obvious and doubtless necessity to obtain qualitative estimates and predict carbon transformations under the conditions of environmental pollution at the background of climate variations. Correct computations of the data related to the emission of $\mathrm{CO}_{2}$ into the atmosphere and to the balance of carbon for the ecosystem related to various naturalclimate zones necessitate obtaining the data of long-term monitoring.

The objectives of the present investigation include: 1) revealing the specific properties bound up with carbon transformations and with carbon balance parameters characteristic of the agroecosystems with grey forest soils depending on technogenic pollution and hydrothermal conditions; 2) assessment of the influence of the environmental factors on the formation of the operating regime of agroecosystems and on the possible levels of their loading.

\section{Objects and Methods of Investigation}

\subsection{The Study Area}

The object of our investigation is represented by the agroecosystems with grey forest soils of Baikal Siberia. According to the norms of geographic zoning, the Irkutsk-Cheremkhovo site $\left(52^{\circ} \mathrm{S}-55^{\circ} \mathrm{S}\right.$ and $\left.100^{\circ} \mathrm{E}-108^{\circ} \mathrm{E}\right)$ belongs to the East-Sayan Province of the forest-steppe zone, which represents its eastern border of Eurasia, which contacts with the zone East-Siberian permafrost-taiga soils. The geological structure of the territory is represented by Cambrian deposits covered with Jurassic ones. The soils are affected by aero-technogenic pollution from industrial enterprises located along the Trans-Siberian railroad and from the corresponding motorway. The largest contribution is made by power plants (66\%) and fuel producing enterprises (12\%). The fact that the arable lands are traditionally close to industrially developed districts of Siberia is one of the causes of soil pollution (mainly with heavy metals (HMs)).

The Irkutsk-Cheremkovo forest-steppe is characterized by sharply continental character of the climate. The mean annual air temperature varies from $-1^{\circ} \mathrm{C}$ to $-3^{\circ} \mathrm{C}$. The temperate-severe and snow-deficient winter lasts for over 5 months. The soils get frozen down to the depth of 2 to $2.5 \mathrm{~m}$ and thaw out very slowly. The frostless period lasts for 75 to 100 days. The spring is short. It is characterized by unstable weather and recurrence of frosts. The moisture content of the soils depends on the autumn reserves of moisture. The summer is short. The mean July temperature is $17.2^{\circ} \mathrm{C}$ to $18.2^{\circ} \mathrm{C}$. The total of the temperatures over $10^{\circ} \mathrm{C}$ is small $\left(1595^{\circ}\right)$. Furthermore, autumn and summer frosts are possible. The annual precipitation varies from 270 to $386 \mathrm{~mm}$, the maximum being characteristic of the warm period (80 to 90 percent of the annual total). The spring and early summer are often arid. The autumn period is short and characterized by unstable weather with the precipitation in the form of rain or sometimes snow. By mid October, the temperature abruptly goes down. The restricted agro-climate resources allow us to consider the scrutinized territory as a zone of risk agriculture. 
The results of generalized analysis of 1) the agro-climate conditions during the recent decades and 2) the expected climate changes in some parts of Russia have been described in the materials prepared by the Russian Federal Department of Hydrometeorology and Environmental Monitoring [12]. On the basis of observations and model-based computations the conclusion has been made that climate changes are directed to warming. The most substantial changes are characteristic of the East-Siberian region. For example, the total surplus of the temperatures over $10^{\circ} \mathrm{C}$ in the recent decade was grown by $94^{\circ} \mathrm{C}$. Meanwhile, the annual amplitude of the temperatures was decreasing more quickly in the southern districts. The vegetation period had become 3 to 4 days longer. Maximum rates of temperature growth (up to $1^{\circ} \mathrm{C}-1.2^{\circ} \mathrm{C}$ ) were registered in July. An obvious reduction of summer precipitation was registered. The hydrothermal coefficient was decreasing.

The cogency of the arguments in favor of the anthropogenic nature of warming may be confirmed by the fact of indirect (mediated) negative influence of technogenic soil pollution. The role of soils in stabilizing the atmosphere gas content is well known [7] [13]. When considering the possibility of reducing the $\mathrm{CO}_{2}$ emission from soils as the factor allowing to soften climate changes, it is necessary to take account of specific natural-climate conditions characteristic of Baikal Siberia as well as ecological consequences of pollution of the arable lands.

\subsection{Research Methods}

The Methodology of our investigations is represented by systems analysis and comparative analysis. The scrutinized agroecosystem is considered as an experimental model of interacting components (soil-microorganisms-plants-atmosphere), which form a system integrated by flows of carbon. As a complete and open system, which is considered as having both spatial-temporal and functional structures, it exists at the expense of coordinated interaction of its components, owing to processes of metabolism and energy exchange inside the system and with the environment.

The regime of functioning and the level of influence upon the agroecosystem were assessed integrally, on the basis of an elaborated and probated approach [14] [15] based on determination of the ratio between the flows of the carbon intra-soil cycle (mineralization $\leftrightarrow$ (re)immobilization). According to our hypothesis, the organic substance of the soil, which undergoes mineralization (M) ("input") forms the two flows: 1) net-mineralized (NM) flow ("output" of the substance from the system) and 2) (re)immobilized (RI) flow ("the process of turning the substance back to the exit", which provides for maintaining the resource of carbon inside the system (feedback). Formation of the RI flow, which is dependent on the activity of the microbial complex in the soil, is considered to be a form of natural homeostatic auto-regulation mechanism maintaining the dynamic equilibrium in the agroecosystem. We have discovered the fact that the compensated character of NM and RI flows favors the formation of the regime, which leads to homeostasis.

The state of the scrutinized agroecosystem was also assessed in terms of the load exerted upon it. For example, in case of some increase in the external effect (load), the regime of functioning was changing, while being graded from stress to resistance or adaptation exhaustion or else repression. The ecological load upon the agroecosystem for each of the regimes was assessed, respectively, as "admissible”, "maximum admissible”, "critical”, "inadmissible".

The regularities related to formation of carbon flows (the ratio NM:RI), which are dependent on variations of the external conditions, have been used for the purpose of a) integrated assessment of the functioning regime (the state) of the agroecosystem and b) normalization of the load. A scale of estimating criteria has been developed [14] [15]. The present paper discusses some results of the related dynamic investigations in the process of long-term (1992-2005) monitoring, which demonstrate variations of the carbon content in the agroecosystem on the whole (soil-microorganisms-plants-atmosphere) and in some of its components. The comparative analysis of the results has allowed us to assess the influences exerted upon the agroecosystem by both the pollutants and the hydrothermal conditions during the years of investigations.

The field experiments have been conducted on grey forest soils either unpolluted or polluted, the sources of pollutants being atmospheric discharges of Sayanskchemplast, Ltd., i.e. mainly heavy metals (HMs). The unpolluted soil of the stationary field, which belongs to Siberian Institute of Plant Physiology and Biochemistry, Siberian Branch, Russian Academy of Sciences, was the check soil sample in the experiments. The influence of hydrothermal conditions upon transformation of carbon during the vegetation period was analyzed in 1994, 2001, 2004, which differed from the average norm for the region during the period 1961-1990. The results were com- 
pared also to the average data for 14 years of monitoring. The integrated assessment of the state of the agroecosystem was conducted during all the years of the monitoring.

These field experiments were conducted in accordance with the technique elaborated earlier [7] [16]. The polluted soil was replaced from the zone of techogenesis to the Institute's stationary field, where earlier the pollution was absent. The profiles of polluted soil were formed at the sites of the stationary field after removing the plough and sub-plough soil layers within the frameworks, which limited the plots of land $\left(1 \mathrm{~m}^{2}\right)$. Such an organization of the experiments has given us the possibility to avoid any uncontrolled effects of soil continued pollution with HMs. All the plots were prepared during the autumn of the previous year, simultaneously for the total rotation of crops (fallow-wheat-wheat). The experiments were repeated with 4 times recurrence. In the process of each of the rotations, mineral (NPK) fertilizers were introduced under the $2^{\text {nd }}$ year spring crops on account of $60 \mathrm{~kg}$ a.i. per hectare, while using only chemically pure salts, which were accurately intermixed within the plough layer. The biological productivity of the spring wheat crops (Triticum aestivum L.) was assessed on the phase of complete ripening.

The properties of the soils and the content of HMs in them were determined before the beginning of the field experiments. The experiments on the fallow and on the wheat crops (after the fallow) presumed the conjugated monitoring of 1) the content carbon in the soil microbial biomass $\left.\left(\mathrm{C}_{\text {micr }}\right), 2\right) \mathrm{CO}_{2}$ emission from the soils (the step being 7 to 14 days from April to October). The values of $\mathrm{C}_{\text {micr }}$ and $\mathrm{C}-\mathrm{CO}_{2}\left(\mathrm{~g} / \mathrm{m}^{2}\right)$ averaged for the vegetation period were computed on account of the density of the plough layer structure. The content of HMs in the soil was measured by the method of atomic absorption [Perkin-Elmer 503]. $\mathrm{C}_{\text {micr }}$ was determined by the rehydration method [17], and the rate of $\mathrm{CO}_{2}$ emission — by the absorption method, while computing the total emission of the season by linear interpolation [18] [19]. The control measurements of $\mathrm{CO}_{2}$ emission were conducted with the aid a gas analyzer (Infralyt-4) according to the technique developed earlier [20]. The air temperature, the temperature of the soils, humidity, precipitation and other environmental parameters were measured simultaneously.

\section{Results}

Some of the agrochemical characteristics of the scrutinized gray forest soils are presented in Table 1 . The polluted (B/HMs) soil differed from unpolluted soil (B), which had lower contents of carbon and nitrogen, although the mobility of these elements was equally high in both soils. In respect to the heavy metal content in the arable soil layer, the both soils differed from one another only very slightly (Table 2). According to the norms approved in Russia, the summary pollution of the soil with HMs was corresponding to the "admissible" level, which did not change even in 14 years of the monitoring.

Variations of the hydrothermal conditions during the vegetation period (May to August) and in different years of the monitoring were considered with respect to the "climatic norm" (for the basic period from 1961 to 1990 [21]). This has allowed us to reveal variations of the air temperature and precipitation totals during the vegetation period and in some years (Table 3). The precipitation totals for the period from May to August and the mean total daily average temperature in 2001 and 2004 were higher than in 1994, when these parameters were

Table 1. Agrochemical characteristics of the investigated soils $(0-20 \mathrm{~cm})$.

\begin{tabular}{ccccc}
\hline Soil & Humus, $\%$ & $\mathrm{~N}_{\text {tot }} \%$ & $\mathrm{pH}_{\mathrm{KCl}}$ & S, mg-equiv/100g of soil \\
\hline $\begin{array}{c}\text { Grey forest (B) } \\
\text { clay loam, unpolluted }\end{array}$ & 4.8 & 0.29 & 5.8 & 27.2 \\
$\begin{array}{c}\text { Grey forest (B/HMs) clay loam, } \\
\text { polluted with heavy metals }\end{array}$ & 2.9 & 0.16 & 5.8 & 22.8 \\
\hline
\end{tabular}

Table 2. Content of heavy metals in the arable of soil, $\mathrm{mg} / \mathrm{kg}$.

\begin{tabular}{cccccccc}
\hline Soil & Cd & Cr & Cu & Hg & Pb & Zh & Mn \\
\hline B & 0.2 & 40 & 25 & 0.04 & 51 & 870 \\
B/HMs & 0.4 & 51 & 22 & 0.2 & 20 & 85 \\
\hline
\end{tabular}


Table 3. The climate parametrs during the years of long-term monitoring in our investigations.

\begin{tabular}{|c|c|c|c|c|c|}
\hline Year & $\begin{array}{l}\text { Precipitation totals, mm } \\
\text { (May-August) }\end{array}$ & $\begin{array}{l}\text { Total daily average } \\
\text { temperature per } \\
\text { May-August, }{ }^{\circ} \mathrm{C}\end{array}$ & $\begin{array}{l}\text { Precipitation } \\
\text { totals per } \\
\text { July, mm }\end{array}$ & $\begin{array}{l}\text { Average air } \\
\text { temperature } \\
\text { per July, }{ }^{\circ} \mathrm{C}\end{array}$ & $\begin{array}{c}\text { HTC } \\
\text { (June-August) }\end{array}$ \\
\hline "Climatic norm"* & 220 & 1300 & 83 & 18 & 1.5 \\
\hline 1994 & 273 & 1290 & 90 & 19 & 1.5 \\
\hline 2001 & 367 & 1945 & 221 & 18 & 1.9 \\
\hline 2004 & 297 & 1469 & 34 & 18 & 2.0 \\
\hline
\end{tabular}

*“Climatic norm” represents average data for 1961-1990 years [21].

close to the "climatic norm”. The highest amount of precipitation was registered in July, 2001. In 1994, the hydrothermal coefficient (HTC) characterizing the degree of humidification in summer period was closer to the "norm”. The values of HTC during 2001 and 2004 years were above the "norm".

The dependence of carbon transformation in land ecosystems on climate conditions is known. There exists also a feedback, i.e. the intensity of transformation processes favors the growth in the concentration of greenhouse gases in the atmosphere, what influences the climate changes. In this connection, both the emission of $\mathrm{CO}_{2}$ from soils and its dependence on technogenic pollution and hydrothermal factors are of substantial scientific interest. The correlation analysis of the monitoring data has shown that the dependence of the $\mathrm{CO}_{2}$ emission rate on the air temperature was positive $(r=0.37-0.46)$, while the dependence on the humidity of the soils was negative ( $r=-0.41--0.47$ ), furthermore, it was independently of the pollution.

As obvious from Table 4, the total C- $\mathrm{CO}_{2}\left(\mathrm{~g} / \mathrm{m}^{2}\right)$ emission values during the vegetation period. In 1994 (the year close to the "norm") were approximately the same in both the fallow and the crops for both of the soils. In unfavorable years, the emission was lower in the fallow for the polluted soil (especially in 2004), while the differences were smaller for the crops with respect to the data for the unpolluted soil. Such regularity was registered also for the indicators of many years. For example, the value average for the years of monitoring characteristic for the fallow for the unpolluted soil was $141 \mathrm{~g} / \mathrm{m}^{2}$, while $125 \mathrm{~g} / \mathrm{m}^{2}$-for the polluted soil.

According to the data for many years, the total $\mathrm{C}-\mathrm{CO}_{2}\left(\mathrm{~g} / \mathrm{m}^{2}\right)$ emission during the vegetation period (110 days) reached the level of $70 \%$ to $75 \%$ of the total annual emission. This may be due to peculiar properties of the local climate: late thawing the soil out in spring; sharp lowering the soil temperature and its fast freezing in autumn. The computations have shown that during the frostless period the loss of carbon owing to $\mathrm{CO}_{2}$ emission on the unpolluted soil in the fallow was $2.8 \%$, and for the wheat crops it was $2.5 \%$, while for the polluted soil the values were larger (respectively, $4.4 \%$ and $3.5 \%$ of the total carbon content in the soil).

The content of $\mathrm{C}_{\text {micr }}$ in the soil was also dependent on the hydrothermal factors (see Table 4). In 1994 (the year close to the "norm"), the content of $\mathrm{C}_{\text {micr }}$ in the polluted soil, was smaller for both the fallow and the crops than that in the unpolluted soil. A similar dependence was also registered in other years, but the values were the smallest for 2004. The data average for the monitoring also showed reduction of the $\mathrm{C}_{\text {micr }}$ content under the influence of HMs.

It is known, under extreme conditions, the strategy of microorganisms is oriented sooner adaptation rather than intensification of growth [22]. In our investigations, unfavorable weather factors, as well as changes in properties of the soil in course of it pollution, led to lowering the $\mathrm{C}_{\text {micr }}$ content, and at the same time- to growth of the rate of $\mathrm{C}-\mathrm{CO}_{2}$ emission. For the purpose of assessment of the energetic productivity (the state) of the microbial complex of the soil under the field conditions we had proposed to employ the value of "specific respiration activity" (SRA, C- $\mathrm{CO}_{2} / \mathrm{C}_{\text {micr }}, \mathrm{mg} / \mathrm{g} \cdot \mathrm{h}$ ) [13]. From the viewpoint of ecophysiology, SRA is equivalent to the "metabolism coefficient" $\mathrm{qCO}_{2}$, which may be determined in laboratory conditions [23] [24]. It was shown that the smaller was the coefficient, the higher was the stability of the soil microorganisms to environmental factors. According the data of our monitoring, the value of SRA average for the vegetation period, which was assessed for the unpolluted soil in the fallow, varied from 0.55 to $0.66 \mathrm{mg} / \mathrm{g} \cdot \mathrm{h}$, while from 0.81 to $0.97 \mathrm{mg} / \mathrm{g} \cdot \mathrm{h}$ for the polluted soil. SRA reached its maximum for the polluted soil in 2004, what indicated to the fact of growth of the carbon expenses needed for adaptation under unfavorable conditions. The value of SRA average for the period 
Table 4. The parametrs of carbon transformation in soils, $\mathrm{g} / \mathrm{m}^{2}$.

\begin{tabular}{|c|c|c|c|c|c|c|c|c|c|c|c|c|c|}
\hline \multirow[b]{2}{*}{ Soil } & \multirow[b]{2}{*}{ Treatment } & \multicolumn{4}{|c|}{$\mathrm{C}_{\text {micr. }}$} & \multicolumn{4}{|c|}{$\mathrm{C}-\mathrm{CO}_{2}$} & \multicolumn{4}{|c|}{$\mathrm{C}-\mathrm{CO}_{2} / \mathrm{C}_{\text {micr }}$ (NM:RI) } \\
\hline & & 1994 & 2001 & 2004 & $\begin{array}{c}\text { Average } \\
\text { long-term } \\
\text { data }\end{array}$ & 1994 & 2001 & 2004 & $\begin{array}{c}\text { Average } \\
\text { long-term } \\
\text { data }\end{array}$ & 1994 & 2001 & 2004 & $\begin{array}{c}\text { Average } \\
\text { long-term } \\
\text { data }\end{array}$ \\
\hline \multirow[t]{2}{*}{ B } & Follow & 103 & 99 & 77 & $93 \pm 6$ & 168 & 162 & 143 & $141 \pm 7$ & 1.6 & 1.6 & 1.9 & 1.5 \\
\hline & Wheat & 91 & 106 & 80 & $94 \pm 7$ & $\begin{array}{c}214 \\
(143)\end{array}$ & $\begin{array}{c}192 \\
(128)\end{array}$ & $\begin{array}{c}173 \\
(116)\end{array}$ & $\begin{array}{c}172 \pm 7 \\
(115)\end{array}$ & 1.6 & 1.2 & 1.5 & 1.5 \\
\hline \multirow[t]{2}{*}{$\mathrm{B} / \mathrm{HMs}$} & Follow & 66 & 61 & 48 & $57 \pm 2$ & 153 & 132 & 128 & $125 \pm 6$ & 2.3 & 2.2 & 2.6 & 2.2 \\
\hline & Wheat & 60 & 55 & 47 & $63 \pm 4$ & $\begin{array}{c}209 \\
(139)\end{array}$ & $\begin{array}{c}196 \\
(130)\end{array}$ & $\begin{array}{c}185 \\
(123)\end{array}$ & $\begin{array}{c}172 \pm 6 \\
(115)\end{array}$ & 2.3 & 2.4 & 2.7 & 1.8 \\
\hline
\end{tabular}

Note: In brackets the data excluding the root respiration.

of our monitoring, which was approximately the same for both the fallow and the crops, but was higher for the polluted soil than for the unpolluted one (respectively, 0.81 and $0.55 \mathrm{mg} / \mathrm{g} \cdot \mathrm{h}$ ), what confirmed the same fact. We revealed that the content of $\mathrm{C}_{\text {micr }}$ was lower for the soil polluted with $\mathrm{HMs}$, while the expenses of carbon needed for respiration $\left(\mathrm{C}-\mathrm{CO}_{2}\right)$ grew. Respectively, the flow of net mineralized carbon (N-M) was larger than the flow of (re)immobilized (RI) carbon, especially in 2001 and 2004 unfavorable with respect to hydrothermal conditions (see Table 4).

Therefore, both of the factors-pollution of the soil with HMs and hydrothermal conditions-negatively influence the soil properties (while including the dynamics of organic matter) and its fertility, what is the cause of direct and mediated impacts the process of carbon transformation in the agroecosystem. Although, in connection with existence of multifactor interrelations in such a complex open dynamic system, it is hardly ever possible to unequivocally define the roles of each of these factors. So, the estimate of behavior and the forecast of the agroecosystem's state under variations of internal and external factors represents a complex problem, whose solution necessitates nonstandard analytical approaches. One of such approaches at the ecosystem level may be approach presuming integrated assessment of the ecological load upon the agroecosystem.

In order to assess the level of influences upon the agroecosystem we employed such an ratio as NM:RI (see Table 4). In all our experiments, the flow of net mineralized (N-M) carbon forming at the expense of microbial respiration was always higher on polluted soils than on unpolluted ones. In 1994, the N-M carbon flow for the polluted soil was 2.3 times as large as the flow of (re)immobilized (RI) carbon, furthermore, for both the fallow and the crops. The largest value of the ratio (2.7) of 2004 was the consequence of negative influence of both the pollution and the unfavorable hydrothermal factors. The average value for monitoring on the whole also demonstrated a larger unbalance of the flows for the polluted soil. According the estimation scale (Table 5), both in separate years and during the cycle of our monitoring, the agroecosystems with unpolluted soils operated in the stress regime ("admissible" load). At the same time, we registered a resistance regime ("maximum admissible" load) for the polluted soil. Consequently, the unbalance between the processes of destruction and synthesis of carbon in agroecosystems containing the soil polluted with HMs grew, especially under unfavorable (with respect to the "norm") weather conditions.

Dynamic variations of the ratio NM:RI obvious from Figure 1 demonstrate the functioning regimes and the load upon the agroecosystem during the years of monitoring (1992-2005). In case of the unpolluted soil, one can observe alternation of homeostasis and stress regimes. The load, which is dependent mainly on variations of hydrothermal conditions, corresponds to the "normal" and "admissible" levels. As shown in [7] [15], in case of agroecosystems characterized by unpolluted grey forest soils, such an alternation of regimes is bound up with the anthropogenic impact of traditional agricultural techniques (for example, with changes of the crops in the crop rotation). The highest load registered during the process of monitoring is characteristic of 1993 (droughty year) and 1999 (rainy year). During the period of observations before 1999, mainly low levels of the load (a regime at the boundary of homeostasis) have been registered. Since 1999, variations of the functioning regime for the agroecosystems are more substantial (stress for the unpolluted soil, resistance for the polluted soil). Formation of new regimes may be considered as a reaction to the change of external conditions (resp. "admissible" and "maximum admissible" loads). It is necessary to add that the minimum load registered in 2000 and 2003 and its sharp increase in subsequent years coincide with changes of the weather conditions. Variations of the regime are more substantial for the polluted soil, what is probably conditioned by the integrated effect of several factors. An 


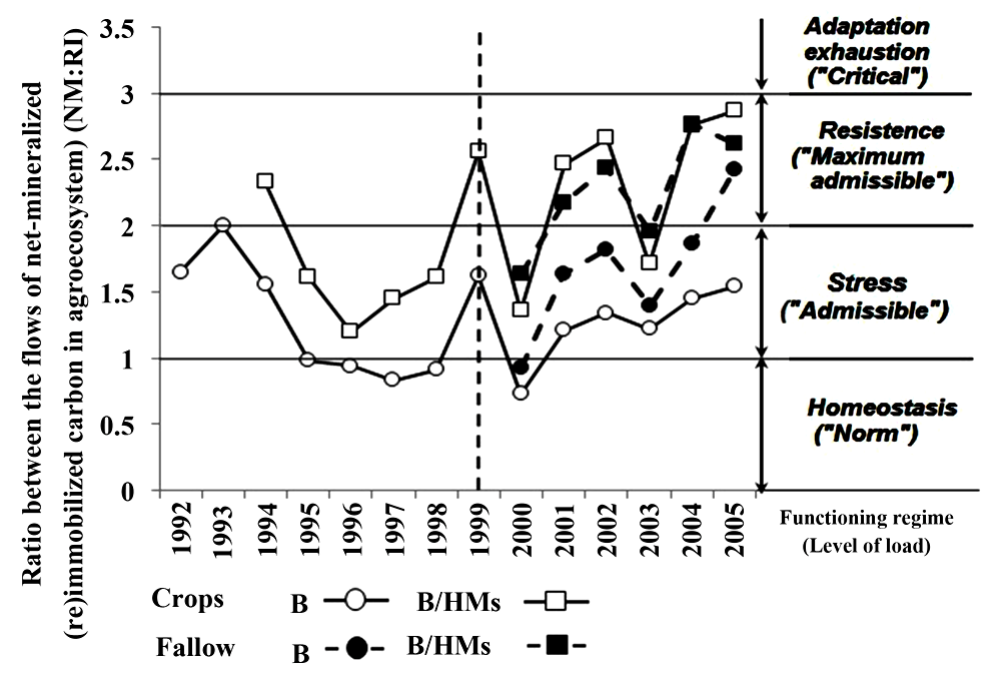

Figure 1. Dynamics of the regime of agroecosystem functioning. Soil: B, unpolluted; B/HMs, with heavy metals.

Table 5. Criteria of functioning regime and level of load on agroecosystem.

\begin{tabular}{|c|c|c|c|}
\hline \multirow{2}{*}{ Functioning regime } & \multirow{2}{*}{ Level of load } & \multicolumn{2}{|c|}{ Criteria } \\
\hline & & RI:M, \%* & N-M:RI \\
\hline Homeostasis & Norm & $50 \pm 5$ & $0.8-1.2$ \\
\hline Stress & Admissible & $45-35$ & $1.2-2.0$ \\
\hline Resistance & Maximum admissible & $35-25$ & $2.0-3.0$ \\
\hline Adaptation exhaustion & Critical & $25-15$ & $3.0-5.0$ \\
\hline Repression & Inadmissible & $<10-15$ & $>5.0$ \\
\hline
\end{tabular}

Note: ${ }^{*}$ Legends in the text.

abrupt change of the regime in 2001, 2003 and 2004 gives evidence of instability of agroecosystems with polluted soils. So, the load corresponds to the "maximum admissible load", and the regime is closer to the adaptation exhaustion (i.e. the "critical" load).

\section{Discussion}

Instability of agroecosystems located upon polluted soils leads to the unpredictable character of their behavior, in particular, under simultaneous effect of the technogenic pollution and the climate factors. The integrated effect of the latter influences the process of formation of carbon flows. These flows may (from our viewpoint) be the direct and reverse feedbacks, which determine the functioning regime of the agroecosystem as an open and dynamically non-equilibrium system. The flow of (re)immobilized carbon ("return from the output", or the feedback) involves newly formed substances, which are formed mainly in the processes of microbiological transformations. According to the theoretical provisions, these newly formed substances may be considered as "dissipative structures", which favor the maintenance of metabolic carbon reserves in the soil, this carbon participating in metabolic processes in the agroecosystem. We assume, the process of formation of the (re)immobilized carbon flow performs the role of the auto-regulation mechanism, which is needed for maintaining the dynamic equilibrium in the agroecosystem [14]. The regulating role of the processes of carbon (re)immobilization is bound up with the capability of the soil microbial complex to compensate for, reduce or increase the expenses needed for adaptation or for the growth. Reduction of (re)immobilized carbon is accompanied by formation of a new regime of functioning of the agroecosystem as a result of complex nonlinear processes of self-organization.

It is known that any ecological investigation necessitates substantial time. The problem of behavior of the 
agroecosystem in response to climate variations and/or to the increase of the level of technigenic pollution cannot be considered as solved even under definite environmental conditions. Practical solution of ecological problems necessitates an optimal strategy. Our experimental material is good enough for conducting systems analysis and may be the basis for mathematical modeling.

\section{Conclusion}

The present paper discussed the results of authors' investigations of carbon transformations in agroecosystems on account of natural-climate factors. These investigations were bound up with the conjugate assessment of the microbial biomass in soils and $\mathrm{CO}_{2}$ emission into the atmosphere. These were conducted on the agroecosystems having grey forest soils (both unpolluted and polluted with heavy metals), which belonged to the territory of Baikal Siberia. A unique technique of integrated assessment of both the agroecosystem's functioning regime and the level of loads upon the agroecosystem was applied. In the process of long-term field experiments the authors discovered the following. The agroecosystems having technogenically polluted soils are characterized by processes of the soil microbial biomass reduction and by an obvious increase of $\mathrm{CO}_{2}$ emission into the atmosphere. Negative changes, which are bound up with carbon transformation, are intensified under unfavorable climate conditions. Intensification of processes of carbon net mineralization and, vice versa, lowering the intensity of processes related to carbon (re)immobilization (especially under the effect of soil pollution and climate changes) provoke instability of the agroecosystem and cause formation of a new regime of its functioning. The integrated assessment gives evidence of some increase of the ecological load upon the agroecosystem (which ranges from a "maximum admissible" level load to a "critical" one) under the simultaneous effect of unfavorable climate factors and technogenic pollution of the soil.

\section{Acknowledgements}

The investigations related to the project have been conducted with the support of grants of Russian Foundation for Basic Research (03-04-49450-a, 05-04-97206 r_Baikal_a, 14-45-04040r_Siberia_a).

\section{References}

[1] Gu, W.B. (2003) Climate Protection Strategies for the 21st Century: Kyoto and Beyond. WBGU—German Advisory Council on GLobal Change, Berlin.

[2] IPCC (2007) Climate Change 2007: The Scientific Report, Contribution of Working Group I to the Fourth Assessment Report of the Intergovernmental Panel on Climate Change. IPCC, Geneva.

[3] IPCC (2013) Climate Change 2013: The Physical Science Basis. Contribution of Working Group I to the Fifth Assessment Report of the Intergovernmental Panel on Climate Change. Cambridge University Press, Cambridge.

[4] Hare, W., Cramer, W., Schaeffer, M., Battaglini, A. and Jaeger, C. (2011) Climate Hotspots: Key Vulnerable Regions, Climate Change and Limits to Warming. Regional Environmental Change, 11, 1-13. http://dx.doi.org/10.1007/s10113-010-0195-4

[5] Lal, R. (2004) Agricultural Activities and the Global Carbon Cycle. Nutrient Cycling in Agroecosystems, 70, $103-116$. http://dx.doi.org/10.1023/B:FRES.0000048480.24274.0f

[6] (2011) Sustaining Soil Productivity in Response to Global Climate Change: Science, Policy, and Ethics. In: Sauer, T., Norman, J. and Sivakumar, M., Eds., Wiley-Blackwell, Hoboken.

[7] Pomazkina, L.V., Kotova, L.G., Lubnina, E.V., Zorina, S.Yu. and Lavrent'yeva, A.S. (2004) The Resistance of Agroecosystems to Fluoride Pollution. IG SD RAS, Irkutsk.

[8] Kudeyarov, V.N. and Kurganova, I.N. (2005) Respiration of Soils in Russia: Database Analysis, Long-Term Monitoring, and General Estimates. European Journal of Soil Science, 38, 993-998.

[9] Kudeyarov, V.N., Demkin, V.A., Gilichinsky, D.A., Gorjachkin, S.V. and Rozhkov, V.A. (2009) Global Changes of a Climate and a Soil Cover. European Journal of Soil Science, 42, 953-966. http://dx.doi.org/10.1134/S1064229309090014

[10] (2007) Agroecosystems in a Changing Climate. In: Newton, P., Edwards, C.R. and Niklaus, G., Eds., CRC Taylor \& Francis.

[11] Bindi, M. and Olesen, J. (2011) The Responses of Agriculture in Europe to Climate Change. Regional Environmental Change, 11, 151-158. http://dx.doi.org/10.1007/s10113-010-0173-x

[12] (2008) Assessment Report on Climate Change and Its Consequences in Russian Federation. General Summary. Mos- 
cow.

[13] Pomazkina, L.V., Kotova, L.G., Zorina, S.Yu., Rybakova, A.V. and Tikhonov, A.Yu. (2008) Carbon Dioxide Emission as Affected by the Properties of Arable Soils Polluted with Fluorides. Eurasian Soil Science, 41, 629-637. http://dx.doi.org/10.1134/S1064229308060082

[14] Pomazkina, L.V. (2004) A New Integral Approach to Evaluation of Functioning Agroecosystems and Ecological Standardization of Anthropogenic Impact, including Technogenic Soil Pollution. Achievements of Modern Biology (in Russian), 124, 66-76.

[15] Pomazkina, L.V. (2009) Integral Assessment of Functioning and Resistance Agroecosystems on Soils Polluted by Aluminum Production Fluorides in the Baikal Siberia. Engineering Ecology (in Russian), 6, 27-42.

[16] Pomazkina, L.V., Kotova, L.G., Zorina, S.Yu. and Rybakova, A.V. (2008) Comparative Assessment of Agroecosystems Developed on Different Types of Soils Contaminated by Fluorides from Aluminum Smelters in the Cis-Baikal Region. Eurasian Soil Science, 41, 202-209. http://dx.doi.org/10.1134/S1064229308020117

[17] Blagodatsky, S.A., Blagodatskaya, E.V., Gorbenko, A.Yu. and Panikov, N.S. (1987) Rehydration Method of Microbe Biomass Determination in Soil. Pochvovedenie (in Russian), 4, 64-71.

[18] Buyanovsky, G.A. and Vagner, G.H. (1987) Carbon Transfer in a Winter Wheat (Triticum aestivum L.) Ecosystem. Biology and Fertility of Soils, 5, 76-82. http://dx.doi.org/10.1007/BF00264350

[19] Pomazkina, L.V., Lubnina, E.V., Zorina, S.Yu. and Kotova, L.G. (1996) Dynamics of $\mathrm{CO}_{2}$ Evolution in Grey Forest Soil of the Baikal Forest-Steppe. Biology and Fertility of Soils, 23, 327-331. http://dx.doi.org/10.1007/BF00335962

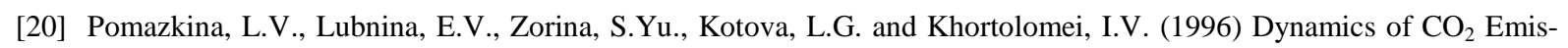
sion from the Gray Forest Soil in the Forest-Steppe of the Cisbaikal Region. Eurasian Soil Science, 29, 1355-1359.

[21] WMO Greenhouse Gas Bulletin (2008) http://www.wmo.int/pages/prog/arep/gaw/ghg/GHGbulletin.html

[22] Lengeler, J., Drews, G. and Schlegel, H. (1999) Biology of the Prokaryotes. Wiley-Blackwell, Hoboken.

[23] Anderson, T.H. and Domsch, K.H. (1990) Application of Eco-Physiological Quotient $\left(q \mathrm{CO}_{2}, q \mathrm{D}\right)$ on Microbial Biomass from Soils of Different Cropping Histories. Soil Biology and Biochemistry, 22, 251-255. http://dx.doi.org/10.1016/0038-0717(90)90094-G

[24] Blagodatskaya, E.V. and Anderson, T.H. (1999) Adaptive Responses of Soil Microbial Communities under Experimental Acid Stress in Controlled Laboratory Studies. Applied Soil Ecology, 11, 207-216.

http://dx.doi.org/10.1016/S0929-1393(98)00148-6 
Scientific Research Publishing (SCIRP) is one of the largest Open Access journal publishers. It is currently publishing more than 200 open access, online, peer-reviewed journals covering a wide range of academic disciplines. SCIRP serves the worldwide academic communities and contributes to the progress and application of science with its publication.

Other selected journals from SCIRP are listed as below. Submit your manuscript to us via either submit@scirp.org or Online Submission Portal.
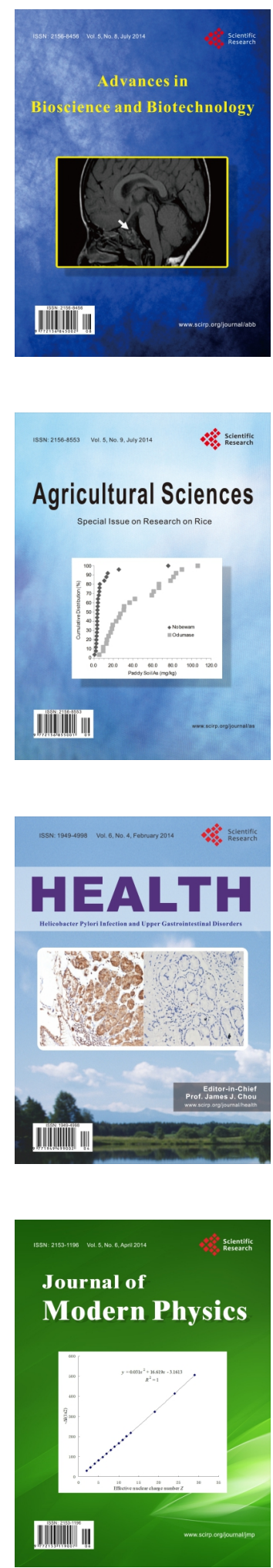
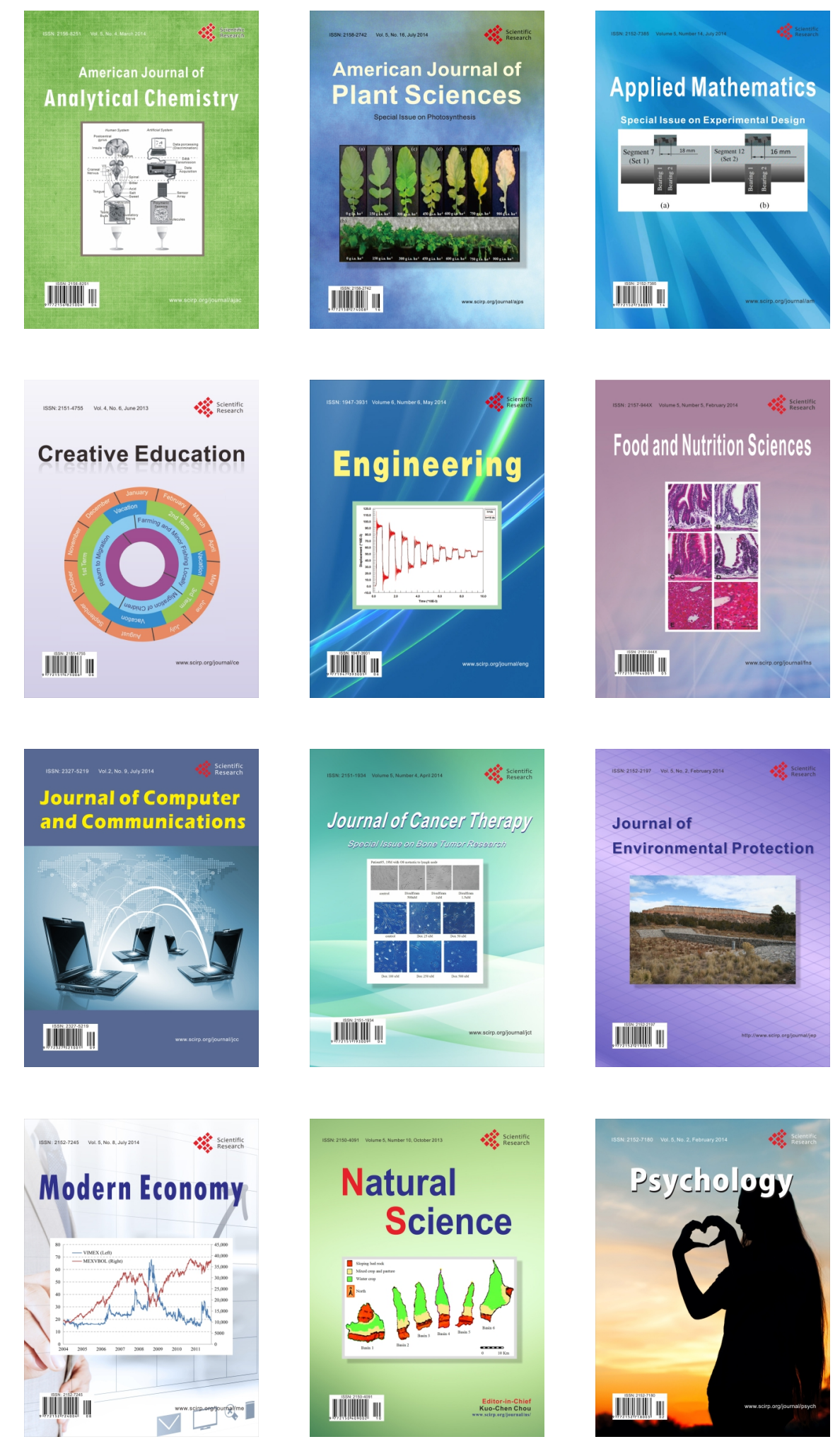